\title{
PTEN genomic deletion predicts prostate cancer recurrence and is associated with low AR expression and transcriptional activity
}

\author{
Khalil Choucair ${ }^{1}$, Joshua Ejdelman ${ }^{1}$, Fadi Brimo ${ }^{2}$, Armen Aprikian$^{1}$, Simone Chevalier $^{1}$ and Jacques Lapointe ${ }^{{ }^{*}}$
}

\begin{abstract}
Background: Prostate cancer (PCa), a leading cause of cancer death in North American men, displays a broad range of clinical outcome from relatively indolent to lethal metastatic disease. Several genomic alterations have been identified in PCa which may serve as predictors of progression. PTEN, (10q23.3), is a negative regulator of the phosphatidylinositol 3-kinase (PIK3)/AKT survival pathway and a tumor suppressor frequently deleted in PCa. The androgen receptor (AR) signalling pathway is known to play an important role in PCa and its blockade constitutes a commonly used treatment modality. In this study, we assessed the deletion status of PTEN along with AR expression levels in 43 primary PCa specimens with clinical follow-up.

Methods: Fluorescence In Situ Hybridization (FISH) was done on formalin fixed paraffin embedded (FFPE) PCa samples to examine the deletion status of PTEN. AR expression levels were determined using immunohistochemistry (IHC).
\end{abstract}

Results: Using FISH, we found 18 cases of PTEN deletion. Kaplan-Meier analysis showed an association with disease recurrence $(P=0.03)$. Concurrently, IHC staining for AR found significantly lower levels of AR expression within those tumors deleted for PTEN $(P<0.05)$. To validate these observations we interrogated a copy number alteration and gene expression profiling dataset of 64 PCa samples, 17 of which were PTEN deleted. We confirmed the predictive value of PTEN deletion in disease recurrence $(P=0.03)$. PTEN deletion was also linked to diminished expression of PTEN $(P<0.01)$ and AR $(P=0.02)$. Furthermore, gene set enrichment analysis revealed a diminished expression of genes downstream of AR signalling in PTEN deleted tumors.

Conclusions: Altogether, our data suggest that PTEN deleted tumors expressing low levels of AR may represent a worse prognostic subset of PCa establishing a challenge for therapeutic management.

Keywords: Prostate cancer, Prognosis, PTEN, AR

\section{Background}

Prostate cancer ( $\mathrm{PCa})$ strongly affects the male population, and is classified as the most commonly diagnosed cancer and a leading cause of cancer death in North American men [1]. The current prognostic tools, such as pre-operative prostate specific antigen (PSA) levels, histological Gleason grading of biopsy specimens and clinical TNM (tumor, node, metastasis) staging seem unable to accurately risk stratify individual $\mathrm{PCa}$ patients at

\footnotetext{
* Correspondence: jacques.lapointe@mcgill.ca

'Department of Surgery, Division of Urology, McGill University and the Research Institute of the McGill University Health Centre(RI-MUHC), Montreal H3G 1A4, QC, Canada

Full list of author information is available at the end of the article
}

early stages of the disease. Given the wide range of clinical outcomes and the heterogeneity of the disease, the main challenge facing physicians remains to distinguish latent from clinically significant tumors. There is thus a clear need for better prognostic markers.

Androgens are required for maintaining the homeostasis of the normal prostate epithelium. Their effect is mediated via the androgen receptors (AR), a member of the nuclear superfamily of steroid receptor, acting as a transcription factor in prostate cell nuclei. PCa cells have retained the ability to proliferate upon stimulation with androgens, resulting in tumor growth [2]. Thus, PCa patients that experience a recurrence following localized

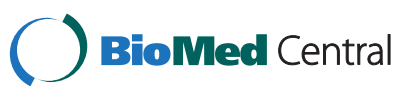


treatment are subjected to androgen deprivation therapy. Although most patients respond well initially to androgen deprivation therapy, almost all of them will eventually experience resistance to treatment and disease progression [3]. Therapeutic options for castrate resistant $\mathrm{PCa}$ (CRPC) are limited to chemotherapy regimens that show a modest survival benefit [4]. There is currently no curative treatment for metastatic PCa. Understanding the molecules and the pathways involved in mediating resistance is thus needed for a better clinical management of the disease.

The phosphatidylinositol 3-kinase (PI3K)/AKT signal transduction pathway contributes to cancer growth and survival, and is activated in a broad range of human malignancies including $\mathrm{PCa}$ [5]. The phosphatase and tensin homologue deleted on chromosome 10 (PTEN) is a tumor suppressor gene on 10q23.3 locus that acts by negatively regulating the PI3K/AKT pathway [6]. In animal models, PTEN was shown to be haploinsufficient in tumor suppression [7]. PTEN genomic deletion has been detected in human tissues representing all stages of $\mathrm{PCa}$ development and progression including High Grade Prostatic Intraepithelial Neoplasia (HGPIN), primary $\mathrm{PCa}$ and at higher frequency in metastatic PCa and CRPC [8-15]. Using Fluorescent in situ hybridization (FISH), PTEN deletion status of primary PCa has been associated with poor outcome [14]. Previous studies in human PCa cell lines and mice models have suggested that inactivation of PTEN and PI3K/AKT activation can modulate AR activity and contribute to CRPC [16-18]. These observations provided further rationale to examine PTEN and AR in human prostate tissues.

In this study, we surveyed PCa samples for genomic DNA copy number alterations (CNAs) of the PTEN gene using Fluorescent in situ hybridization (FISH) and AR expression by immunohistochemistry (IHC). An existing PCa microarray dataset of DNA CNAs by array comparative genomic hybridization $(\mathrm{CGH})$ and corresponding gene expression profiling were used to validate these findings.

\section{Methods}

\section{Ethics statement}

This study was conducted with the written consent of the participants and approved by the Research Ethics Board of the McGill University Health Centre (study BMD-10-115).

\section{Tissue samples}

Formalin fixed paraffin embedded (FFPE) blocks ( $n=43$ ) of primary tumors and adjacent benign tissues from radical prostatectomy were retrieved from the Department of Pathology. Duplicate tissue cores (1mm diameter) were assembled into tissue microarrays (TMAs). Haematoxylin and eosin (H\&E)-stained TMA sections were reviewed to determine the presence of representative areas of the original samples. The clinicopathologic features of the cohort are summarized in Table 1. Recurrence-free interval was defined as the time between date of surgery and the date of first PSA increase $>0.2 \mathrm{ng} / \mathrm{ml}$ or the date of last follow-up without PSA increase (censored). Kaplan-Meier survival analysis (log-rank test) was performed using WinStat (R. Fitch Software).

\section{Fluorescent in situ hybridization (FISH)}

Dual-color FISH was carried out on TMA sections using the BAC clone RP11-383D9 (BACPAC Resources Center, Oakland, CA) mapping to the PTEN gene on chromosome $10 \mathrm{q} 23.3$ region and the commercially available CEP10 Spectrum Green probe (CEP 10, Abbott Molecular, Abbott Park, IL), which spans the 10p11.1q11.1 centromeric region. RP11-383D9 DNA was labeled with Spectrum Orange-dUTP (Enzo Life Science, Farmingdale, NY) using the Nick Translation Reagent Kit (Abbott Molecular). The $5 \mu \mathrm{m}$ TMAs sections were de-paraffinized in 6 changes of xylene before immersion in $95 \%$ ethanol. The slides were then placed in $0.2 \mathrm{~N} \mathrm{HCl}$ solution at room temperature $\left(\mathrm{RT}^{\circ}\right)$ for $20 \mathrm{~min}$ followed by a 2 -hour incubation at $80^{\circ} \mathrm{C}$ in 10 $\mathrm{mM}$ citric acid buffer $(\mathrm{pH}$ 6) for pre-treatment. Specimens were digested in $0.1 \mathrm{mg} / \mathrm{ml}$ protease I (Abbott Molecular), and then fixed for $10 \mathrm{~min}$ in formalin before dehydration in an ethanol series. The two probes and target DNA were co-denatured at $73^{\circ} \mathrm{C}$ for $6 \mathrm{~min}$ and left to hybridize at $37^{\circ} \mathrm{C} \mathrm{O} / \mathrm{N}$ using the ThermoBrite system (Abbott Molecular). Post-hybridization washes were performed in $2 \times \mathrm{xSC}$ and $0.3 \% \mathrm{NP} 40$ / $0.4 \mathrm{xSSC}$ at $73^{\circ} \mathrm{C}$ for $2 \mathrm{~min}$ and $1 \mathrm{~min}$ respectively, followed by a $30 \mathrm{sec}$ incubation at $\mathrm{RT}^{\circ}$ in $2 \mathrm{xSSC}$.

\section{FISH data analysis}

In order to evaluate the 10q23.3 copy number, we counted fluorescent signals in 100 non-overlapping interphase

Table 1 Clinicopathologic parameters of the study subjects

\begin{tabular}{ll}
\hline Median age (range, years) & $\mathbf{n = 4 3}$ \\
\hline Median follow-up (months) & $63(47-76)$ \\
\hline Median PSA at surgery $(\mathbf{n g} \cdot \mathbf{m l}-\mathbf{1})$ & 62 \\
\hline Biochemical recurrence & 8.7 \\
\hline Gleason score & $12(28 \%)$ \\
\hline$\leq 6$ & \\
\hline$=7$ & $13(30 \%)$ \\
\hline$\geq 8$ & $23(54 \%)$ \\
\hline Pathological stage & $7(16 \%)$ \\
\hline$\leq \mathrm{T} 2$ & $27(63 \%)$ \\
\hline$\geq \mathrm{T} 3$ & $16(37 \%)$ \\
\hline
\end{tabular}


nuclei for each sample. 4',6-Diamidino-2-phenylindole (DAPI III, Abbott Molecular) staining of nuclei with reference to the corresponding H\&E-stained tissue identified the areas of adenocarcinoma. Using hybridization in 30 benign control cores, 10q23.3 deletion was defined as $\geq 15 \%$ (mean +3 standard deviation in non-neoplastic controls as described $[19,20]$ ) of tumor nuclei containing one or no 10q23.3 locus signal and by the presence of two CEP10 signals. Images were acquired with an Olympus IX-81 inverted microscope at 96X magnification using ImageProPlus 7.0 software (MediaCybernetics, Rockville, MD).

\section{Immunohistochemistry (IHC) staining}

Immunostaining of AR on TMAs sections was performed using a mouse anti-AR antibody (N-terminal AR 441, NeoMarker, Fremont, CA) and the Envision detection kit (Dako, Carpinteria, CA). The $5 \mu \mathrm{m}$ TMAs sections were de-paraffinized in a series of xylene and hydrated in a graded series ethanol solutions. Heatinduced antigen retrieval was performed by immersing the slides in $10 \mathrm{mM}$ citric acid buffer solution $(\mathrm{pH} 6)$ and boiling for $30 \mathrm{~min}$ using microwave energy. The slides were left in solution to cool down for $30 \mathrm{~min}$ at room temperature. Endogenous peroxydase activity was
A

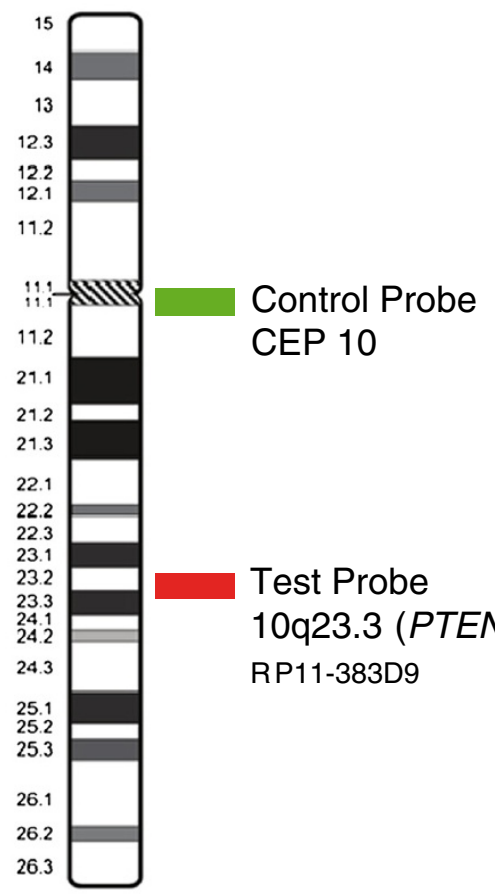

B

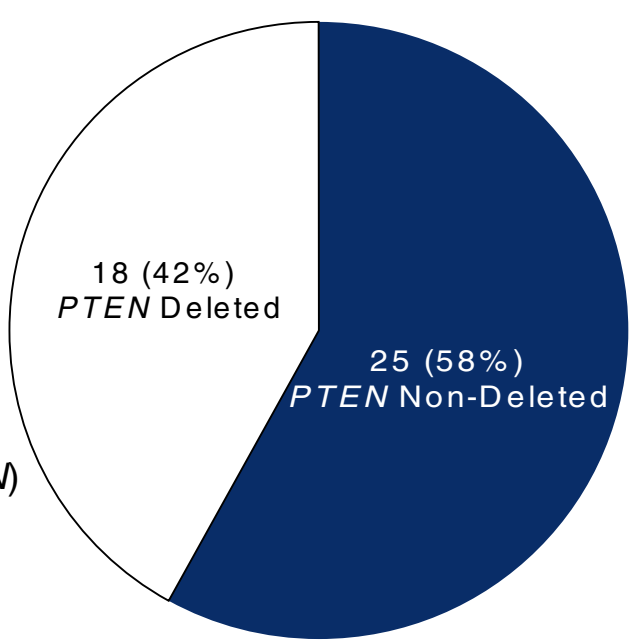

C

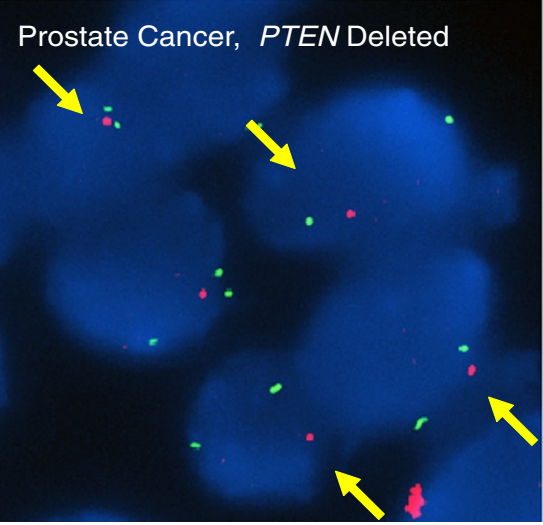

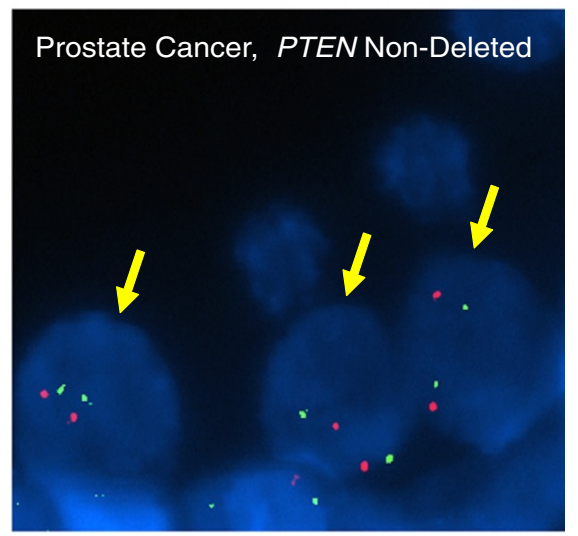

Figure 1 Dual color FISH analysis of PTEN deletion in primary PCa. A) BAC DNA mapping to chromosome 10q23.3 (PTEN) was fluorescently labelled and co-hybridized with fluorescent Centromere 10 control probe to detect PTEN deletion in tumor samples. B) PTEN deletion status of 43 primary PCa samples determined by FISH. C) FISH for PTEN status in representative interphase nuclei of prostate samples. On the left panel, the FISH image shows 1 red signal (10q23.3 locus) and two green signals (centromere 10) per nuclei indicating a PTEN deletion. On the right panel, the FISH image shows two red signals and two green signals in the nuclei indicating no PTEN deletion. 


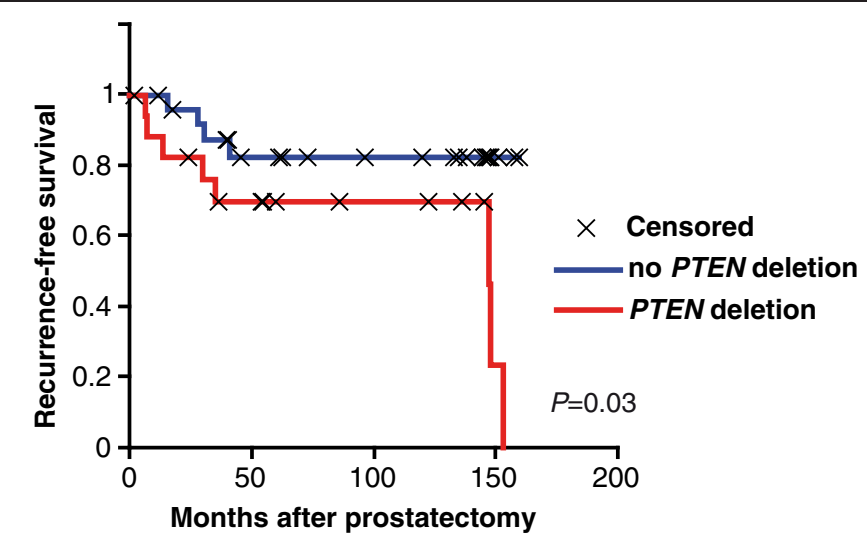

$\begin{array}{lrrrr}\text { Patients at risk } & & & & \\ \text { no PTEN deletion } 25 & 17 & 13 & 4 \\ \text { PTEN deletion } & 18 & 11 & 7 & 2\end{array}$

Figure 2 Prognostic value of PTEN deletion in PCa. Kaplan-Meier recurrence-free survival analysis based on PTEN deletion status determined by FISH ( $n=43)$. P-value (log-rank test) indicated.

blocked for 5 minutes (Dako). After a 60 min block with $10 \%$ normal goat serum in PBS (Dako), the primary antibody (1:50 dilution in Dako antibody diluent) was used for two hours at room temperature. Chromogenic detection was carried out using a peroxidase-conjugated secondary antibody $(30 \mathrm{~min})$ and DAB reagents $(10 \mathrm{~min})$ provided with the Envision detection kit. Tissue sections were counterstained with Meyer's Haematoxylin (Thermo Scientific, Waltham, MA).

\section{IHC data analysis}

Nuclear staining was assessed by two independent observers using the $\mathrm{H}$-score method described in [21,22]. Briefly, $\mathrm{H}$-score was obtained by computing the product of staining intensity ( $\mathrm{i}=0-3)$ and the proportion of cells with the specific intensity (0-100), in areas of adenocarcinoma as identified with reference to the corresponding $\mathrm{H} \& \mathrm{E}$-stained tissue. The $\mathrm{H}$-scores were adjusted to give the highest score a value of 100 . AR $\mathrm{H}$-scores were
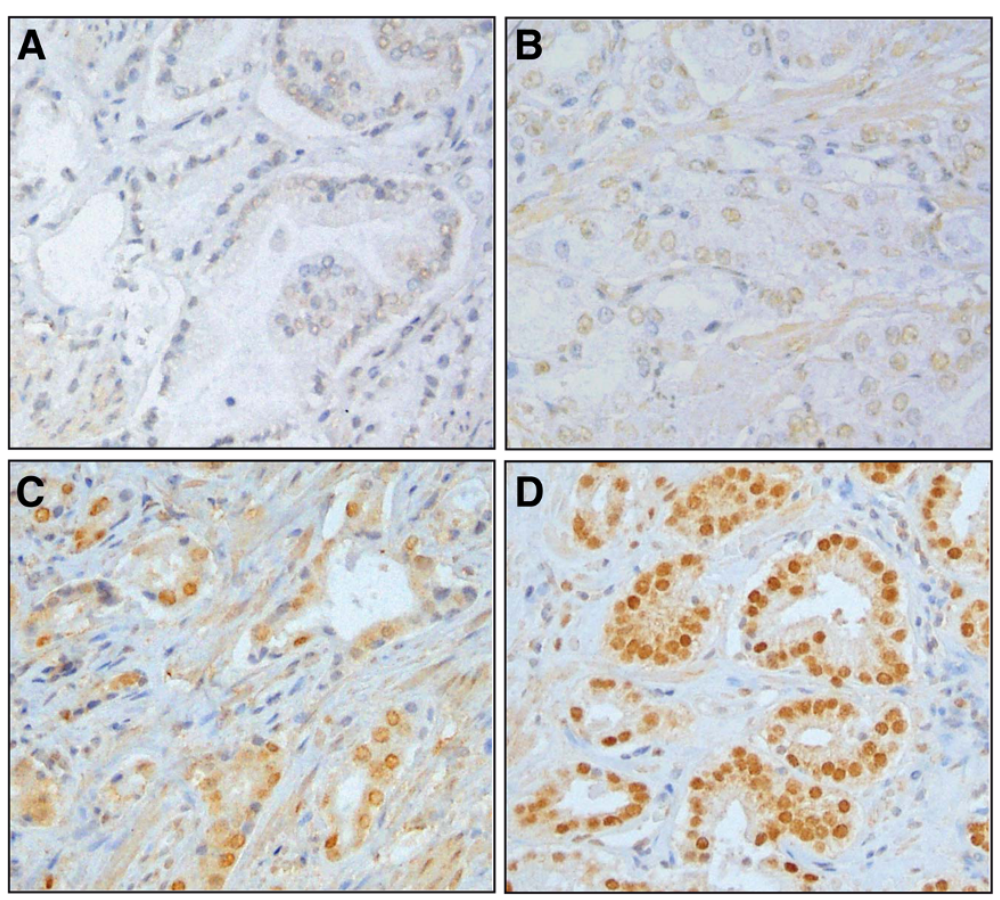

Figure 3 AR IHC staining of PCa. Examples of nuclear AR staining corresponding to the variation of the adjusted $\mathrm{H}$-score scale with $\mathbf{A}=10$, $\mathbf{B}=28, \mathbf{C}=71$ and $\mathbf{D}=76$. Original magnification 200X. 
compared between PTEN deleted and non deleted specimens categories with the Mann-Whitney $U$-Test (http:// elegans.som.vcu.edu/ leon/stats/utest.html).

\section{Gene set enrichment analysis (GSEA)}

Analysis [23] was performed using GSEA software version 2.07 (Broad Institute, Cambridge, MA) with the previously published gene expression data of 64 prostate tumors by Lapointe et al. [24] stratified by their PTEN genomic status as reported in the corresponding array CGH study [9]. Two androgen-responsive gene sets (R1881-treated LNCaP cells) were tested for enrichment in the gene expression microarray data: a curated set of 82 genes (NELSON_RESPONSE_TO_ANDROGEN_UP, [25]) from the Molecular Signatures database (MSigDB, C2) and a set of 207 genes reported by DePrimo et al. [26]. Lapointe et al gene expression study used for GSEA included data for respectively 71 and 204 genes of Nelson et al. and DePrimo et al. androgen-responsive gene sets. A thousand permutations were done and the false discovery rate (FDR) was estimated.

\section{Results}

\section{FISH analysis and PTEN deletion status}

We used FISH to assess the genomic status of PTEN at chromosome 10q23.3 on TMAs representing 43 cases of human PCa with clinical follow-up. The clinicopathologic characteristics of the study subjects are summarized in Table 1. We found that 18 of 43 tumors harbor a hemizygous deletion of PTEN (Figure 1). No homozygous deletion was detected in these samples. We did not find any significant association between PTEN status and tumor Gleason score, surgical stage, and preoperative PSA levels of patients (data not shown). To further evaluate the clinical significance of the PTEN deletion, we stratified the 43 cases based on their PTEN deletion status and performed a Kaplan-Meier survival analysis. Figure 2 shows that PTEN deletion was associated with a significant shorter time to recurrence $(\mathrm{P}=0.03)$.

\section{IHC and AR expression}

We used the same set of tumors to estimate the levels of nuclear AR expression by IHC. For each sample, the $\mathrm{H}$-score was calculated to take into account the proportion of stained cells on the TMA cores as well as the intensity of the nuclear staining. The range of the $\mathrm{H}$-score adjusted to 100 varied across the samples from 10 to 100 (median=70, $\mathrm{n}=43$ ). AR immunostaining of specimens with different $\mathrm{H}$-scores are shown as examples in Figure 3. In these samples, AR immunostaining was not significantly associated with the Gleason score, surgical stage, preoperative PSA, and recurrence (not shown). However we found that the AR expression was significantly lower in $\mathrm{PCa}$ tumors harboring a PTEN deletion compared to those with no deletion of PTEN $(\mathrm{P}<0.05$, Figure 4).

\section{PTEN deletion and AR expression in gene expression and DNA copy number alterations dataset}

To confirm our observations, we examined a previously published PCa gene expression study [24], for which the PTEN deletion status was assessed by array CGH [9]. This independent data set of $64 \mathrm{PCa}$ samples included 29 cases with clinical follow-up. We found that 17 of 64 tumors harbor a deletion of PTEN which was significantly associated with a reduced levels of PTEN mRNA $(P<0.01$, Figure 5A). A Kaplan-Meier survival analysis performed on the 29 cases with clinical follow-up revealed that the PTEN deletion was associated with early disease recurrence $(P=0.03$, Figure $5 \mathrm{~B})$. The PTEN deletion was also associated with a reduced levels of AR mRNA ( $P=0.02$, Figure 6). However, AR mRNA levels did not predict biochemical recurrence in these samples (data not shown).

\section{Androgen-regulated genes and PTEN deletion}

To assess whether the reduced AR levels of expression observed in PTEN deleted tumors had consequences on AR signalling, we performed GSEA on the microarray data of the 64 PCa stratified by their PTEN genomic status.

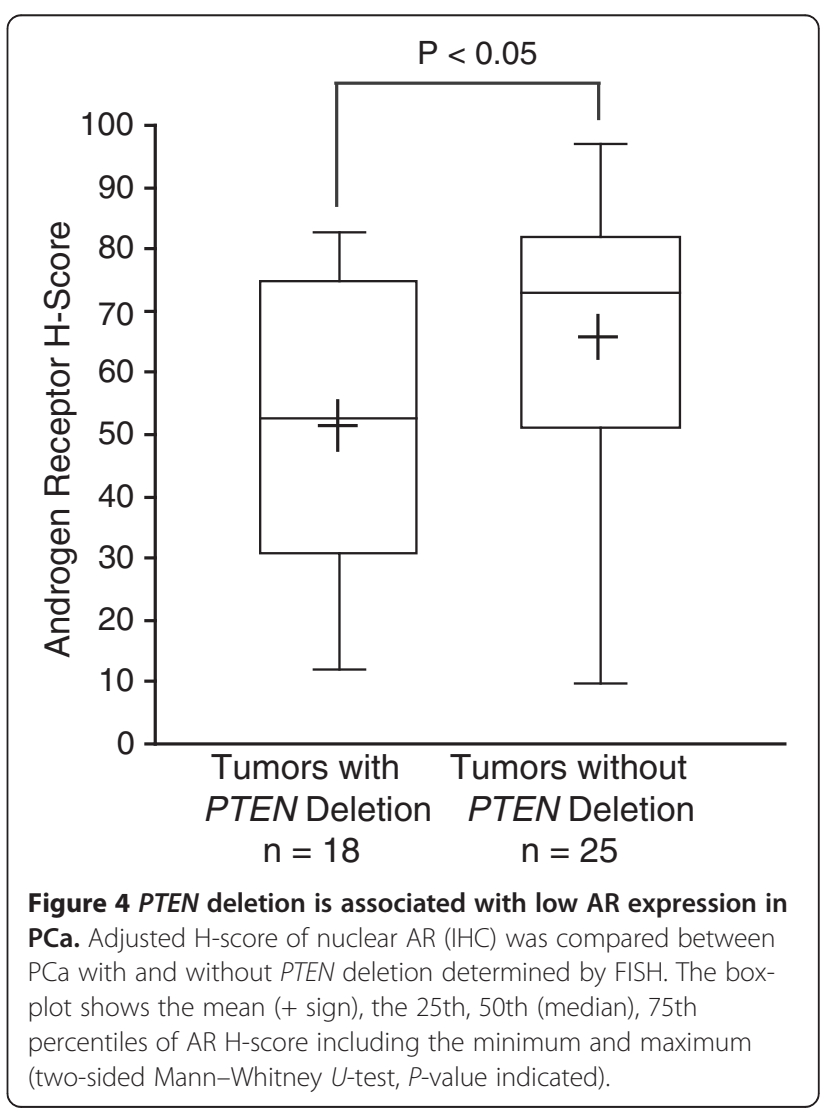



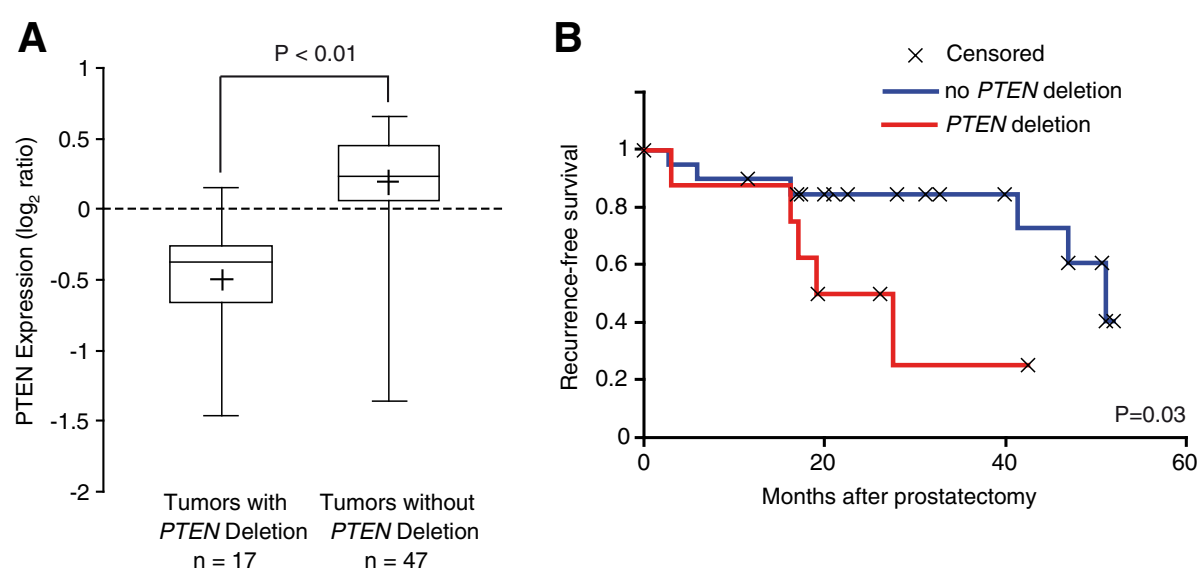

Figure 5 PTEN deletion predicts disease recurrence in an independent PCa cohort. A) In the dataset of Lapointe et al., PTEN deletion status of 64 PCa as determined by array CGH was associated with low PTEN mRNA levels measured by gene expression profiling. The box-plot shows the mean (+ sign), the 25th, 50th (median), 75th percentiles of PTEN expression including the minimum and maximum (unequal variance $t$-test, $P$ Value indicated). Values are reported as log2 ratios, normalized to the sample-set mean. B) Kaplan-Meier analysis of recurrence-free survival based on PTEN deletion status of a subset of the PCa cohort for which the clinical follow-up was available ( $\mathrm{n}=29$ ). P-value (log-rank test) indicated.

GSEA is a computational method that determines whether an a priori defined set of genes shows statistically significant, concordant differences between two phenotypes [23], in our case the PTEN status. We first tested a curated gene set from the molecular signature database

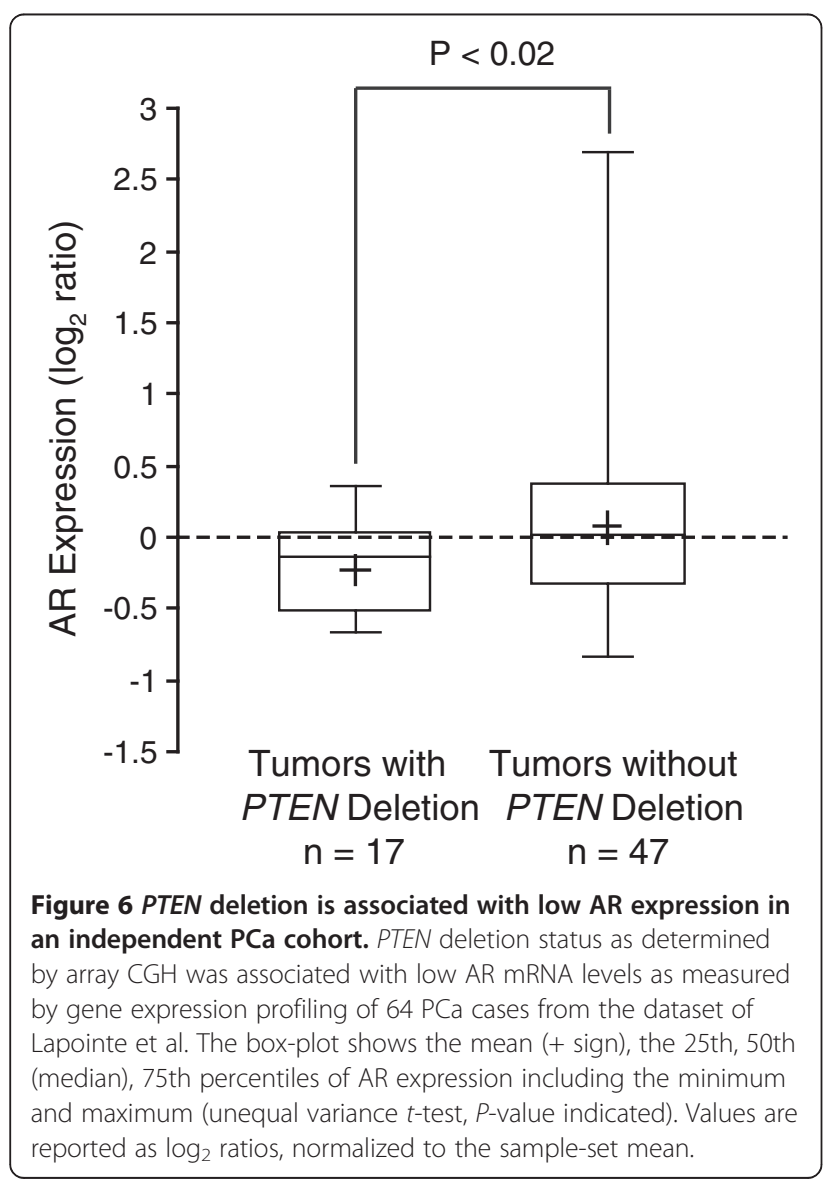

(MSigDB,C2) identified as NELSON_RESPONSE_TO_ ANDROGEN_UP, [25]. The plot in Figure 7A shows the significant enrichment of the AR-regulated genes in tumors with no deletion of PTEN compared to those with a deletion (FDR of 0.01). To further confirm this result, we tested a second set of androgen regulated genes reported by DePrimo et al. [26] and found also an enrichment of expression of these genes in tumors with no PTEN deletion (FDR $=0.13$, Figure $7 \mathrm{~B})$. Genes from Nelson et al. that significantly contribute to the enrichment core are shown in Figure 7C.

\section{Discussion}

In this study, we have shown in two independent sets of PCa samples that the PTEN genomic deletion was associated with early disease recurrence and reduced levels of AR expression. In microarray gene expression data, the PTEN deletion was also associated with a down regulation of AR-driven genes.

The frequency of PTEN deletion in our FISH study $(40 \%)$ is within the range of previous reports $[8,10,12,14,15]$. Our survival analysis further confirms the association of PTEN genomic deletion and poor outcome of PCa reported earlier [14] and its potential use as a prognostic marker. Clinical relevance is also supported by the recent literature detecting PTEN deletion at high frequency in CRPC samples [11], in circulating tumor cells [27] and its association with $\mathrm{PCa}$ death $[11,28]$. Further validation in larger cohorts would be critical to compare its predictive value with the current prognostication tools.

The intriguing finding of our study was the reduced levels of AR expression quantified by $\mathrm{H}$-score in tumors harboring a PTEN deletion. We found a similar 

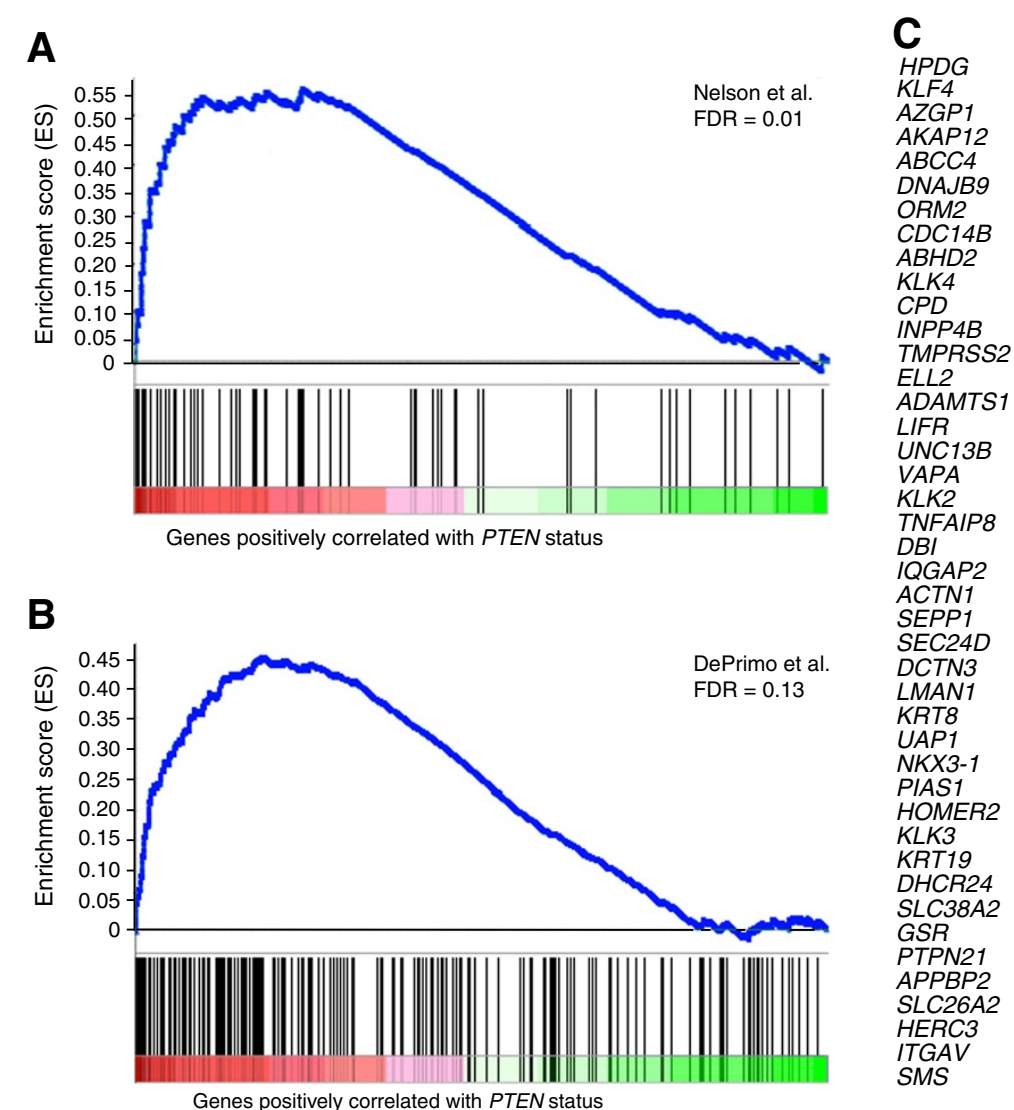

Figure 7 PTEN status is associated with AR signalling. GSEA was performed with previously published gene expression data of 64 prostate tumors (Lapointe et al.) stratified by their PTEN genomic status. Two androgen responsive gene sets were tested: A) a curated set of 71 genes (NELSON_RESPONSE_TO_ANDROGEN_UP, Nelson et al.) from the Molecular Signatures database (MSigDB, C2) and B) a set of 204 genes reported by DePrimo et al. GSEA identified enrichment of androgen responsive genes in PTEN positive samples. The enrichment score (ES, $y$-axis) reflects the degree to which an androgen responsive gene set is overrepresented at the top ranked list of genes according to the PTEN status (ranked in descending order from left to right, $x$-axis). Enrichment is evidenced by the early positive deflection of the running sum curve (blue line).

A thousand permutations were done and the false discovery rate estimated (FDR). C) Genes from Nelson et al. that contribute to the enrichment core.

association between PTEN deletion and AR transcript levels in a $\mathrm{PCa}$ microarray dataset. The differential expression of AR according to the PTEN tumor status has not been well documented so far. A pilot IHC study has found a positive correlation between AR and PTEN expression [29]. In contrast, Sircar et al. reported a positive correlation between PTEN deletion status and AR expression [11] in CRPC samples. These results likely reflect two different stages of the disease: CRPC and untreated $\mathrm{PCa}$. The genomic amplification of AR is known to occur in CRPC but rarely in untreated PCa [30], thereby explaining differences in results.

Previous in vitro studies in cell lines derived from advanced PCa suggested that PTEN could act as suppressor of AR activity [31,32]. It was also reported that the activation of PI3K/AKT pathway can suppress the AR activity in low passage $\mathrm{LNCaP}$ and enhance AR activity in high passage, hence suggesting modulation as cells evolve towards less responsive status [33]. In models representing less advanced disease, re-expression of PTEN in PTEN null murine cells did not affect AR expression, but upregulated the AR transcriptional activity [34]. Another group reported that PTEN null murine prostate cells had a reduced AR protein levels compared to wild-type PTEN cells and the AR protein levels were partly restored by the PI3K/mTOR inhibitor BEZ235 [35]. The latter observation would suggest that the activation of PI3K pathway may in part explain the reduced AR levels in PTEN deleted tumors. A shown by Lin et al., it is also possible that PTEN interacts directly with AR and promotes its degradation [31]. Underlying mechanisms of how PTEN deletion in human tumors is associated with lower AR expression and transcriptional activity need to be further explored.

Given their reduced levels of AR expression, the PTEN deleted tumor cells are expected to be less responsive to androgen ablation treatment. In support of 
this hypothesis, it was reported that CRPC and early biochemical recurrence were associated with reduced immunoreactivity of PTEN and AR in the PCa samples harvested before treatment initiation [29]. The addition of an inhibitor of PI3K/mTOR to the standard androgen ablation treatment of advanced PCa may therefore be beneficial to patients with PTEN deleted tumor.

Some previous studies have found that low levels of AR were associated with PCa recurrence [36,37] while others reported the opposite [38,39]. In our study, AR levels of expression were not significantly associated with PCa recurrence. The antibody used, IHC technique and scoring methods may explain the differences in the findings. Given the limited number of patients of our study, a detailed analysis of AR and PTEN in a large cohort of patients with follow-up is warranted.

During the course of our study, two groups also showed a reduced expression of androgen regulated genes in human PTEN deleted PCa by microarray analysis [34,35]. In our analysis, the androgen regulated genes enriched in tumor with no deletion of PTEN include genes expressed in normal prostate luminal epithelium such as KLK3 (PSA), TMPRSS2, and NKX3-1. Of interest, the list includes AZGP1 previously reported as a surrogate marker for subtype-1 tumors, a favourable prognostic subclass of $\mathrm{PCa}$ defined by gene expression pattern analysis [24]. AZGP1 prognostic value was further confirmed by two other studies [40,41]. Previous GSEA has also revealed enrichment of androgenresponsive genes in subtype-1 tumors [42]. Consistant with our findings, the confirmation of intact PTEN status in subtype- 1 tumors from the array CGH data may, at least in part, explain their androgen-regulated gene expression feature and good clinical outcome.

\section{Conclusions}

Although limited by the small sample size of this study, our preliminary data support that PTEN deletion is associated with $\mathrm{PCa}$ recurrence and may thus serve as prognostic marker. As proposed, the low expression of AR and its target genes associated with PTEN deletion may have consequences on response to androgen ablation therapy and may be an indication for the introduction of additional therapeutic modalities.

\section{Competing interests}

The authors declare that they have no competing interests.

\section{Authors' contributions}

Conceived and designed the experiments: $\mathrm{KC}_{1} J \mathrm{E}_{1} \mathrm{JL}$. Performed the experiments: KC, JE. Analyzed the data: KC, JE, FB, JL. Contributed materials/ clinical data: AA. Wrote the paper: KC, JE, SC, JL. All authors read and approved the final manuscript.

\section{Acknowledgments}

We would like to thank Kanishka Sircar for his initial help in creating the TMAs used in this study and Eleonara Scarlata for aiding with the histological assessment of tissue sections. Furthermore, we would like to acknowledge Karl-Philippe Guérard for his critical reading and his help in the preparation of the manuscript. This study was support by Prostate Cancer Canada Pilot Grant and Fonds recherche Québec - Santé (FRQS) to JL and by the McGill Division of Urology and John McCrae Studentships to KC.

\section{Author details}

${ }^{1}$ Department of Surgery, Division of Urology, McGill University and the Research Institute of the McGill University Health Centre(RI-MUHC), Montreal H3G 1A4, QC, Canada. ${ }^{2}$ Department of Pathology, McGill University and the Research Institute of the McGill University Health Centre(RI-MUHC), Montreal H3G 1A4, QC, Canada.

Received: 31 August 2012 Accepted: 10 November 2012

Published: 22 November 2012

\section{References}

1. Canadian Cancer Society's Steering Committee on Cancer Statistics: Canadian Cancer Statistics 2011. Toronto: Canadian Cancer Society; 2011.

2. Bentel JM, Tilley WD: Androgen receptors in prostate cancer. J Endocrinol 1996, 151:1-11.

3. Yuan X, Balk SP: Mechanisms mediating androgen receptor reactivation after castration. Urol Oncol 2009, 27:36-41.

4. Petrylak DP, Tangen CM, Hussain MH, Lara PN Jr, Jones JA, Taplin ME, Burch PA, Berry D, Moinpour C, Kohli M, et al: Docetaxel and estramustine compared with mitoxantrone and prednisone for advanced refractory prostate cancer. N Engl J Med 2004, 351:1513-1520.

5. Li L, Ittmann MM, Ayala G, Tsai MJ, Amato RJ, Wheeler TM, Miles BJ, Kadmon D, Thompson TC: The emerging role of the PI3-K-Akt pathway in prostate cancer progression. Prostate Cancer Prostatic Dis 2005, 8:108-118.

6. Stambolic V, Suzuki A, de la Pompa JL, Brothers GM, Mirtsos C, Sasaki T, Ruland J, Penninger JM, Siderovski DP, Mak TW: Negative regulation of PKB/Akt-dependent cell survival by the tumor suppressor PTEN. Cell 1998, 95:29-39.

7. Trotman LC, Niki M, Dotan ZA, Koutcher JA, Di Cristofano A, Xiao A, Khoo AS, Roy-Burman P, Greenberg NM, Van Dyke T, et al: Pten dose dictates cancer progression in the prostate. PLOS Biol 2003, 1:E59.

8. Ishkanian AS, Mallof CA, Ho J, Meng A, Albert M, Syed A, van der Kwast T, Milosevic M, Yoshimoto M, Squire JA, et al: High-resolution array CGH identifies novel regions of genomic alteration in intermediate-risk prostate cancer. Prostate 2009, 69:1091-1100.

9. Lapointe J, Li C, Giacomini CP, Salari K, Huang S, Wang P, Ferrari M, Hernandez-Boussard T, Brooks JD, Pollack JR: Genomic profiling reveals alternative genetic pathways of prostate tumorigenesis. Cancer Res 2007, 67:8504-8510.

10. McCall P, Witton CJ, Grimsley S, Nielsen KV, Edwards J: Is PTEN loss associated with clinical outcome measures in human prostate cancer? Br J Cancer 2008, 99:1296-1301.

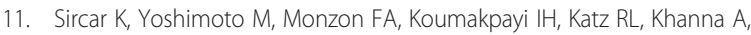
Alvarez K, Chen G, Darnel AD, Aprikian AG, et al: PTEN genomic deletion is associated with $\mathrm{p}$-Akt and AR signalling in poorer outcome, hormone refractory prostate cancer. J Pathol 2009, 218:505-513.

12. Taylor BS, Schultz N, Hieronymus H, Gopalan A, Xiao Y, Carver BS, Arora VK, Kaushik $P$, Cerami E, Reva B, et al: Integrative genomic profiling of human prostate cancer. Cancer Cell 2010, 18:11-22.

13. Verhagen PC, van Duijn PW, Hermans KG, Looijenga LH, van Gurp RJ, Stoop $H$, van der Kwast TH, Trapman J: The PTEN gene in locally progressive prostate cancer is preferentially inactivated by bi-allelic gene deletion. J Pathol 2006, 208:699-707.

14. Yoshimoto M, Cunha IW, Coudry RA, Fonseca FP, Torres CH, Soares FA, Squire JA: FISH analysis of 107 prostate cancers shows that PTEN genomic deletion is associated with poor clinical outcome. $\mathrm{Br} J$ Cancer 2007, 97:678-685.

15. Yoshimoto M, Cutz JC, Nuin PA, Joshua AM, Bayani J, Evans AJ, Zielenska M, Squire JA: Interphase FISH analysis of PTEN in histologic sections shows genomic deletions in $68 \%$ of primary prostate cancer and $23 \%$ of highgrade prostatic intra-epithelial neoplasias. Cancer Genet Cytogenet 2006, 169:128-137.

16. Bertram J, Peacock JW, Fazli L, Mui AL, Chung SW, Cox ME, Monia B, Gleave $\mathrm{ME}$, Ong CJ: Loss of PTEN is associated with progression to androgen independence. Prostate 2006, 66:895-902. 
17. Jiao J, Wang S, Qiao R, Vivanco I, Watson PA, Sawyers CL, Wu H: Murine cell lines derived from Pten null prostate cancer show the critical role of PTEN in hormone refractory prostate cancer development. Cancer Res 2007, 67:6083-6091.

18. Wu Z, Conaway M, Gioeli D, Weber MJ, Theodorescu D: Conditional expression of PTEN alters the androgen responsiveness of prostate cancer cells. Prostate 2006, 66:1114-1123.

19. Fuller CE, Schmidt RE, Roth KA, Burger PC, Scheithauer BW, Banerjee R, Trinkaus K, Lytle R, Perry A: Clinical utility of fluorescence in situ hybridization (FISH) in morphologically ambiguous gliomas with hybrid oligodendroglial/astrocytic features. J Neuropathol Exp Neurol 2003, 62:1118-1128.

20. Raghavan R, Balani J, Perry A, Margraf L, Vono MB, Cai DX, Wyatt RE, Rushing EJ, Bowers DC, Hynan LS, White CL III: Pediatric Oligodendrogliomas: A Study of Molecular Alterations on 1p and 19q Using Fluorescence In Situ Hybridization. J Neuropathol Exp Neurol 2003, 62:530-537.

21. Bosman FT, de Goeij AF, Rousch M: Quality control in immunocytochemistry: experiences with the oestrogen receptor assay. J Clin Pathol 1992, 45:120-124.

22. Aasmundstad TA, Haugen OA, Johannesen E, Hoe AL, Kvinnsland S: Oestrogen receptor analysis: correlation between enzyme immunoassay and immunohistochemical methods. J Clin Pathol 1992, 45:125-129.

23. Subramanian A, Tamayo P, Mootha VK, Mukherjee S, Ebert BL, Gillette MA, Paulovich A, Pomeroy SL, Golub TR, Lander ES, Mesirov JP: Gene set enrichment analysis: a knowledge-based approach for interpreting genome-wide expression profiles. Proc Natl Acad Sci USA 2005, 102:15545-15550.

24. Lapointe J, Li C, Higgins JP, van de Rijn M, Bair E, Montgomery K, Ferrari M, Egevad L, Rayford W, Bergerheim U, et al: Gene expression profiling identifies clinically relevant subtypes of prostate cancer. Proc Natl Acad Sci USA 2004, 101:811-816.

25. Nelson PS, Clegg N, Arnold H, Ferguson C, Bonham M, White J, Hood L, Lin $B$ : The program of androgen-responsive genes in neoplastic prostate epithelium. Proc Natl Acad Sci USA 2002, 99:11890-11895.

26. DePrimo SE, Diehn M, Nelson JB, Reiter RE, Matese J, Fero M, Tibshirani R, Brown PO, Brooks JD: Transcriptional programs activated by exposure of human prostate cancer cells to androgen. Genome Biol 2002, 3:RESEARCH0032.

27. Attard G, Swennenhuis JF, Olmos D, Reid AH, Vickers E, A'Hern R, Levink R, Coumans F, Moreira J, Riisnaes R, et al: Characterization of ERG, AR and PTEN gene status in circulating tumor cells from patients with castration-resistant prostate cancer. Cancer Res 2009, 69:2912-2918.

28. Reid AH, Attard G, Ambroisine L, Fisher G, Kovacs G, Brewer D, Clark J, Floh P, Edwards S, Berney DM, et al: Molecular characterisation of ERG, ETV1 and PTEN gene loci identifies patients at low and high risk of death from prostate cancer. Br J Cancer 2010, 102:678-684.

29. El Sheikh SS, Romanska HM, Abel P, Domin J, el Lalani N: Predictive value of PTEN and AR coexpression of sustained responsiveness to hormonal therapy in prostate cancer--a pilot study. Neoplasia 2008, 10:949-953.

30. Visakorpi T, Hyytinen E, Koivisto P, Tanner M, Keinanen R, Palmberg C, Palotie A, Tammela T, Isola J, Kallioniemi OP: In vivo amplification of the androgen receptor gene and progression of human prostate cancer. Nat Genet 1995, 9:401-406.

31. Lin HK, Hu YC, Lee DK, Chang C: Regulation of androgen receptor signaling by PTEN (phosphatase and tensin homolog deleted on chromosome 10) tumor suppressor through distinct mechanisms in prostate cancer cells. Mol Endocrinol 2004, 18:2409-2423.

32. Nan B, Snabboon T, Unni E, Yuan XJ, Whang YE, Marcelli M: The PTEN tumor suppressor is a negative modulator of androgen receptor transcriptional activity. J Mol Endocrinol 2003, 31:169-183.

33. Lin HK, Hu YC, Yang L, Altuwaijri S, Chen YT, Kang HY, Chang C: Suppression versus induction of androgen receptor functions by the phosphatidylinositol 3-kinase/Akt pathway in prostate cancer LNCaP cells with different passage numbers. J Biol Chem 2003, 278:50902-50907.

34. Mulholland DJ, Tran LM, Li Y, Cai H, Morim A, Wang S, Plaisier S, Garraway IP, Huang J, Graeber TG, Wu H: Cell autonomous role of PTEN in regulating castration-resistant prostate cancer growth. Cancer Cell 2011, 19:792-804

35. Carver BS, Chapinski C, Wongvipat J, Hieronymus H, Chen Y, Chandarlapaty S, Arora VK, Le C, Koutcher J, Scher H, et al: Reciprocal feedback regulation of PI3K and androgen receptor signaling in PTEN-deficient prostate cancer. Cancer Cell 2011, 19:575-586.

36. Diallo JS, Aldejmah A, Mouhim AF, Fahmy MA, Koumakpayi IH, Sircar K, Begin LR, Mes-Masson AM, Saad F: Co-assessment of cytoplasmic and nuclear androgen receptor location in prostate specimens: potential implications for prostate cancer development and prognosis. BJU Int 2008, 101:1302-1309.

37. Schafer W, Funke PJ, Kunde D, Rausch U, Wennemuth G, Stutzer H: Intensity of androgen and epidermal growth factor receptor immunoreactivity in samples of radical prostatectomy as prognostic indicator: correlation with clinical data of long-term observations. J Urol 2006, 176:532-537.

38. Henshall SM, Quinn DI, Lee CS, Head DR, Golovsky D, Brenner PC, Delprado W, Stricker PD, Grygiel JJ, Sutherland RL: Altered expression of androgen receptor in the malignant epithelium and adjacent stroma is associated with early relapse in prostate cancer. Cancer Res 2001, 61:423-427.

39. Li R, Wheeler T, Dai H, Frolov A, Thompson T, Ayala G: High level of androgen receptor is associated with aggressive clinicopathologic features and decreased biochemical recurrence-free survival in prostate: cancer patients treated with radical prostatectomy. Am J Surg Pathol 2004, 28:928-934.

40. Descazeaud A, de la Taille A, Allory Y, Faucon H, Salomon L, Bismar T, Kim R, Hofer MD, Chopin D, Abbou CC, Rubin MA: Characterization of ZAG protein expression in prostate cancer using a semi-automated microscope system. Prostate 2006, 66:1037-1043.

41. Henshall SM, Horvath LG, Quinn DI, Eggleton SA, Grygiel JJ, Stricker PD, Biankin AV, Kench JG, Sutherland RL: Zinc-alpha2-glycoprotein expression as a predictor of metastatic prostate cancer following radical prostatectomy. J Natl Cancer Inst 2006, 98:1420-1424.

42. Lapointe J, Malhotra S, Higgins JP, Bair E, Thompson M, Salari K, Giacomini CP, Ferrari M, Montgomery K, Tibshirani R, et al: hCAP-D3 Expression Marks a Prostate Cancer Subtype With Favorable Clinical Behavior and Androgen Signaling Signature. Am J Surg Pathol 2008, 32:205-209.

doi:10.1186/1471-2407-12-543

Cite this article as: Choucair et al:: PTEN genomic deletion predicts prostate cancer recurrence and is associated with low AR expression and transcriptional activity. BMC Cancer 2012 12:543.

\section{Submit your next manuscript to BioMed Central and take full advantage of:}

- Convenient online submission

- Thorough peer review

- No space constraints or color figure charges

- Immediate publication on acceptance

- Inclusion in PubMed, CAS, Scopus and Google Scholar

- Research which is freely available for redistribution

Submit your manuscript at www.biomedcentral.com/submit 